\title{
CONSUMING RUSSIA
}



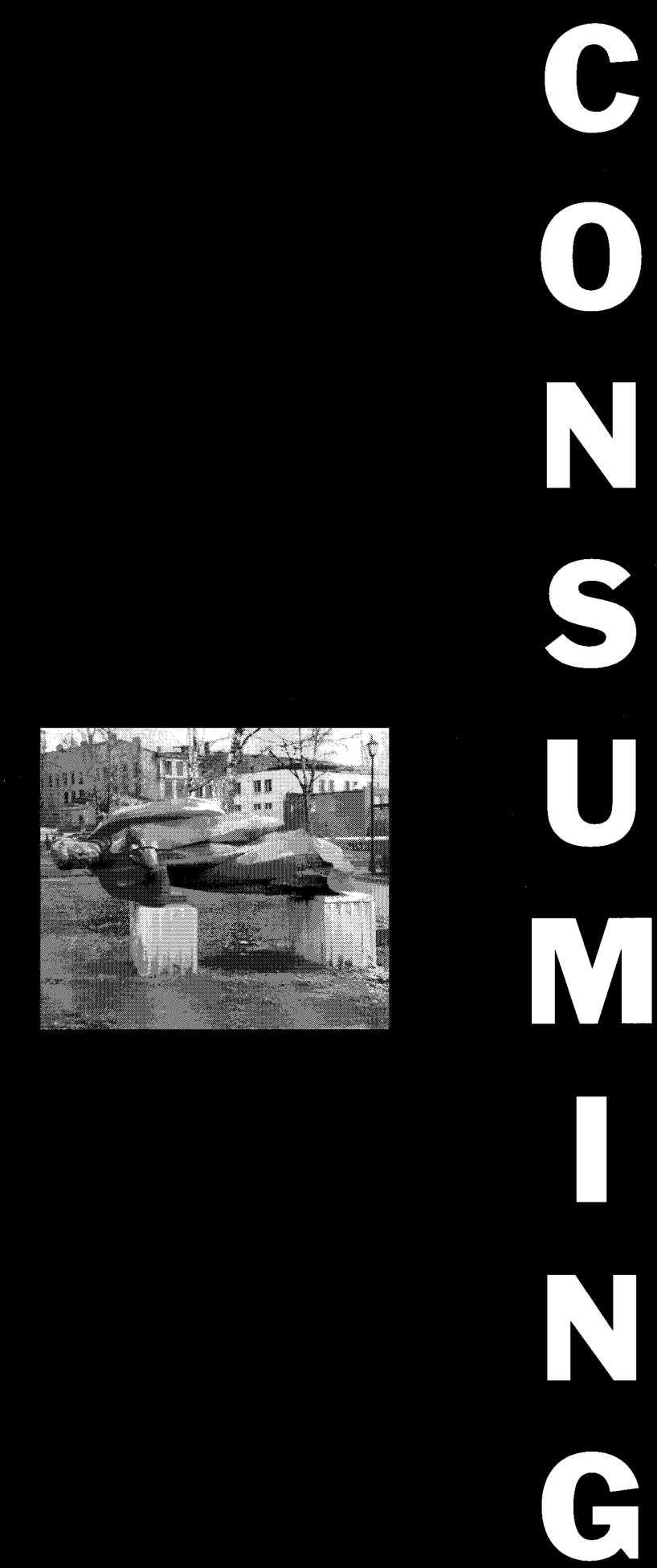
POPulaR

CULTURE,

SEX, AND

SOCIETY

SINCE

GORBACHEV
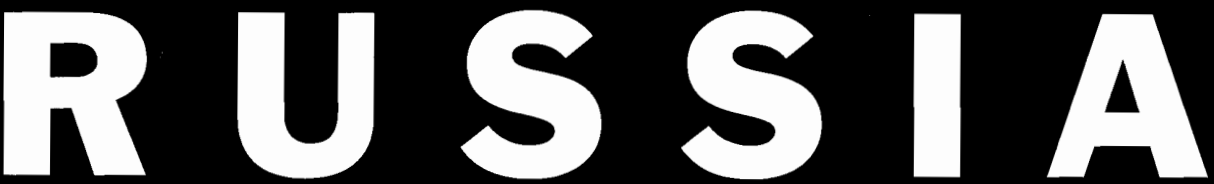

EDITED BY ADELE MARIE BARKER

9
8
9
7
$z$
0
0
2
0
+
+
5
0
0
0
0

DUKE UNIVERSITY PRESS 
C I 999 Duke University Press
All rights reserved
Printed in the United States of America
on acid-free paper $\infty$
Designed by Deborah Wong
Typeset in Times Roman by Keystone Typesetting, Inc.
Library of Congress Cataloging-in-Publication Data
appear on the last printed page of this book. 
To the memory of my Father

Jack Porter Barker

(I9II-I998)

and

Charles Isenberg

(I944-I997) 
